\title{
Wacker and VIA optronics Intensify Collaboration
}

$\bigvee$ acker and VIA optronics have en their cooperation in the field of optical bonding and, in doing so, to bundle their sales and marketing activities. They have also agreed to share more knowledge in developing new products and processing technologies.

Wacker has being supplying VIA optronics with highly transparent silicone gels since 2011. These kinds of silicones make it possible to manufacture low-reflection and energy-saving displays and touchscreens for mobile electronic devices.

VIA optronics has many years of experience in manufacturing and enhancing displays and is a pioneer in optical bonding. The company, which is based in Germany, specialises in reducing display reflections. These kinds of reflections can severely restrict the possible uses of LCDs. They are caused by a design constraint that requires a gap between the cover glass or touchscreen and makes it possible for reflections to occur. This can significantly impair the readability of the display, especially in direct sunlight. The optical bonding process employed by VIA optronics largely eliminates reflections because it uses a transparent silicone gel to bond the full surface of the touchscreen to the LCD. Laminated displays are not only more brilliant and readable, they also consume comparatively little power, because less energy is required to il-

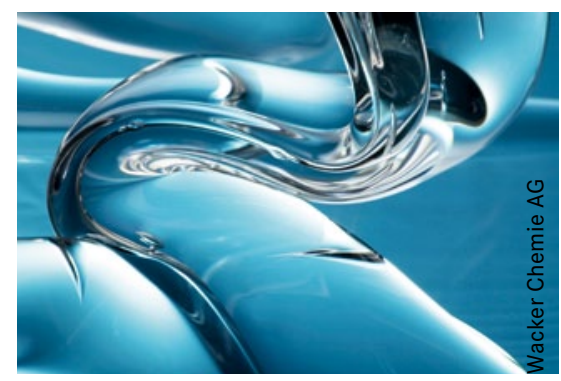

Silicon gels from Wacker protect sensitive electronic components and make the manufacture of low-reflection liquid crystal displays possible luminate the display. In addition, the silicone bond offers protection against dust and moisture and increases the mechanical stability.

For the optical bonding, VIA optronics uses a specialty silicone gel that was custom developed specifically for this purpose by Wacker. The room-temperature-curing gel is highly transparent, highly elastic and slightly tacky. The latter ensures optimum bonding of the components.

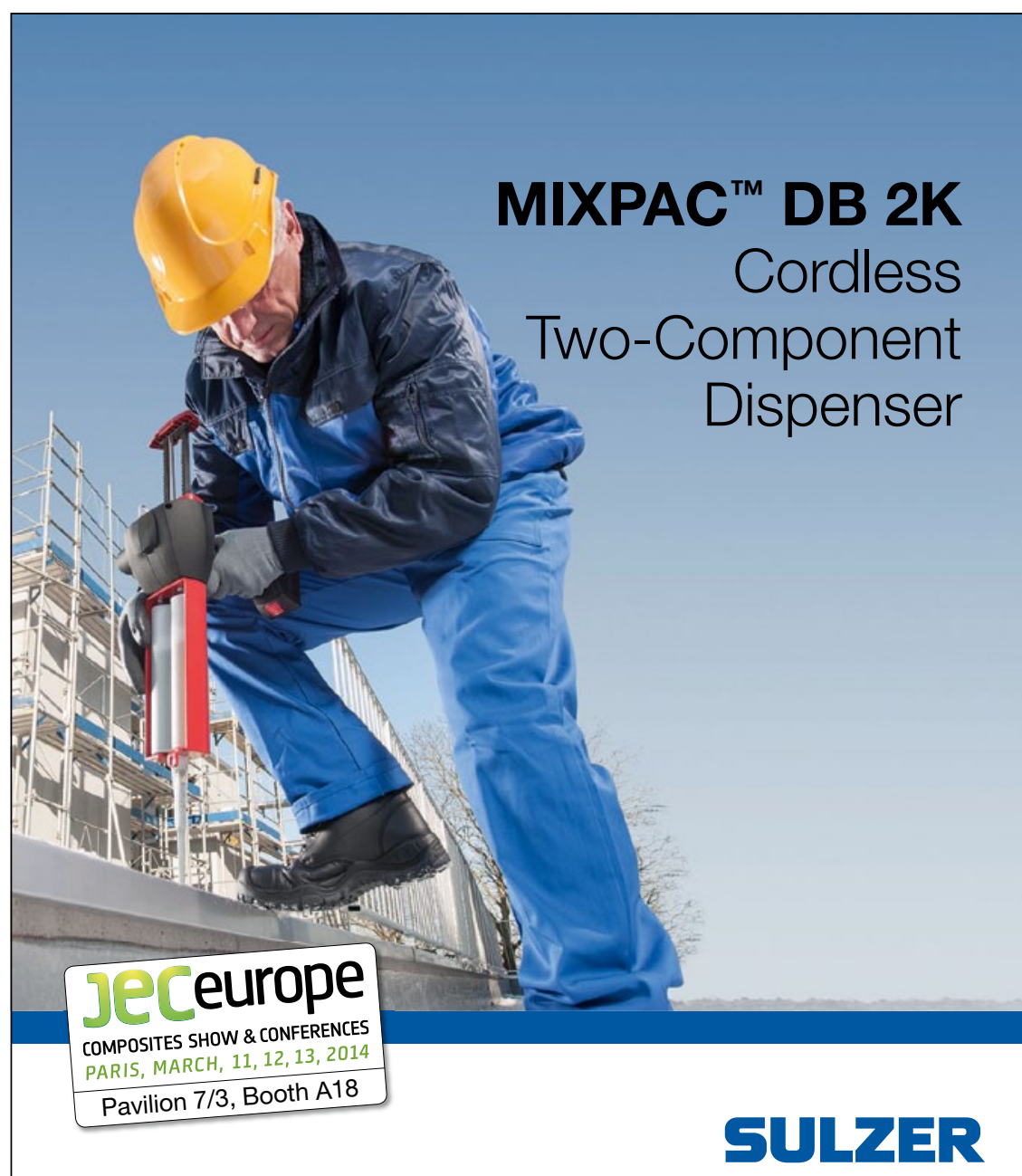

\section{Best versatility and highest reliability in its class!}

The MIXPAC DB 2K from Sulzer with its 18 Volt $\mathrm{Li}$-Ion battery is the strongest cordless dispenser for two-component materials. Its design and various features ensure outstanding performance with two-component applications on every construction site.

\author{
Sulzer Mixpac Ltd \\ Rütistrasse 7 \\ 9469 Haag, Switzerland \\ phone +41817722000 \\ fax $\quad+41817722001$ \\ mixpac@sulzer.com \\ www.sulzer.com
}

